\title{
Amelogenesis Imperfecta - A Rare Inherited Enamel Defect - A Series of Two Cases
}

Sreelakshmi N Nair* and Athul Santhosh

Oral Medicine and Radiology, Private Practitioner, Santhosh Dental Clinic, India

*Corresponding author: Sreelakshmi N Nair, MDS, Oral Medicine and Radiology, Private Practitioner, "Santhosh Dental Clinic", Suhas Tower, Kanhangad, Kasargod Dist, Kerala, India

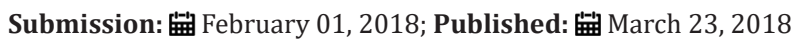

\section{Abstract}

Amelogenesis imperfecta represents a group of developmental conditions, genomic in origin, which affects the structure and clinical appearance of enamel of all or nearly all the teeth. It should be promptly diagnosed and treated so that the dentition can be protected and conserved as much as possible.

\section{Case 1}

A 16 year old female patient presented with a chief complaint of discolored teeth. Medical history and family history were non contributory. No other family member had the same dental problem. Extraoral examination did not reveal any relevant findings. On intraoral examination, there was generalized yellowing and attrition of all surfaces of the teeth (Figure 1A). Wear facets could be seen on lower right posterior teeth with mild chipping off of the tooth surfaces (Figure 1B). A Provisional Diagnosis of Amelogenesis Imperfect was given based on the history and clinical findings. Radiological examination revealed that all the teeth showed a decreased contrast between the enamel and the dentine. The incisal and the occlussal surfaces appeared attrited. The morphology and pulp chamber appeared normal (Figure 2). A Final Diagnosis of Amelogenesis imperfect was given was based on the clinical and radiological diagnosis.
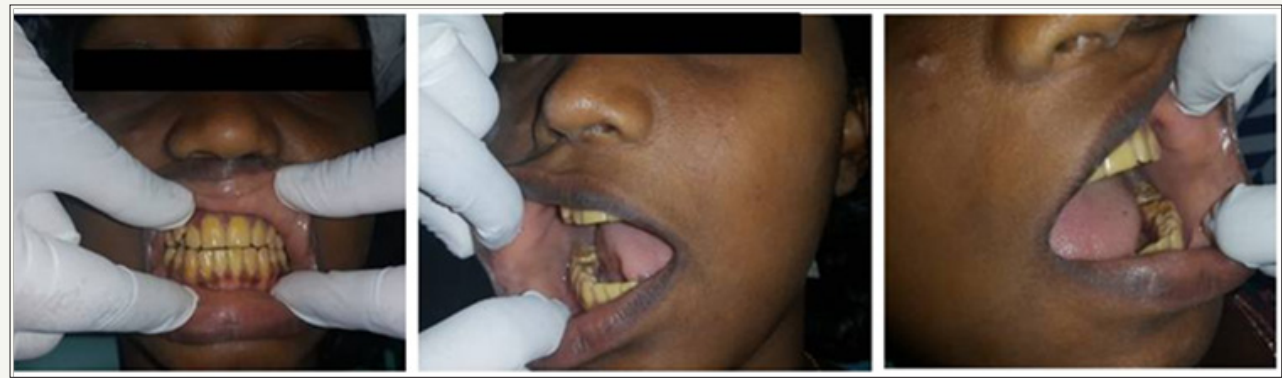

Figure 1A: Generalized yellowing and attrition of all surfaces of the teeth. 1B: Lower right posterior teeth with mild chipping off of the tooth surfaces.

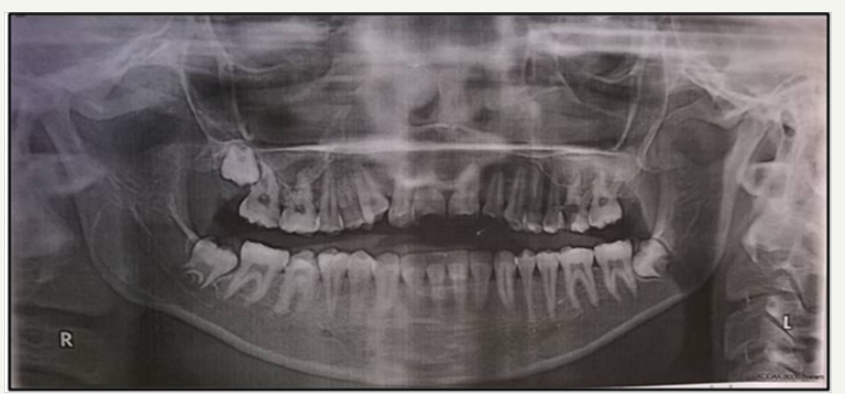

Figure 2: Morphology and pulp chamber appeared normal. 


\section{Case 2}

A 22 year old medically fit male patient, reported with a complaint of discolored teeth since childhood. Family history revealed that similar discoloration of teeth in was seen in his elder sister. No other family members were affected. On intraoral examination: there was generalised yellowish colour noted on all the teeth on all the surfaces (Figure 3A). Chipping off of cusp was seen on lower right posterior teeth with hypoplastic area on upper right front tooth and enamel pitting in upper left front tooth. On mandibular anteriors, there was only minimal attrition seen. Angles Class I malocclusion with anterior deep bite was present (Figure 3B). A Provisional Diagnosis of Amelogenesis imperfect was given.

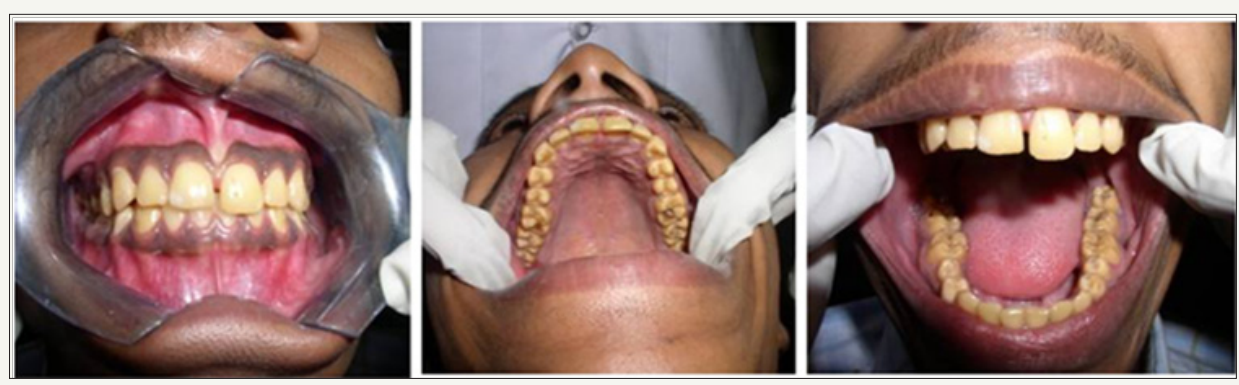

Figure 3A: Generalised yellowish colour noted on all the teeth on all the surfaces. 3B: Angles Class I malocclusion with anterior deep bite was present.

\section{Investigations performed}

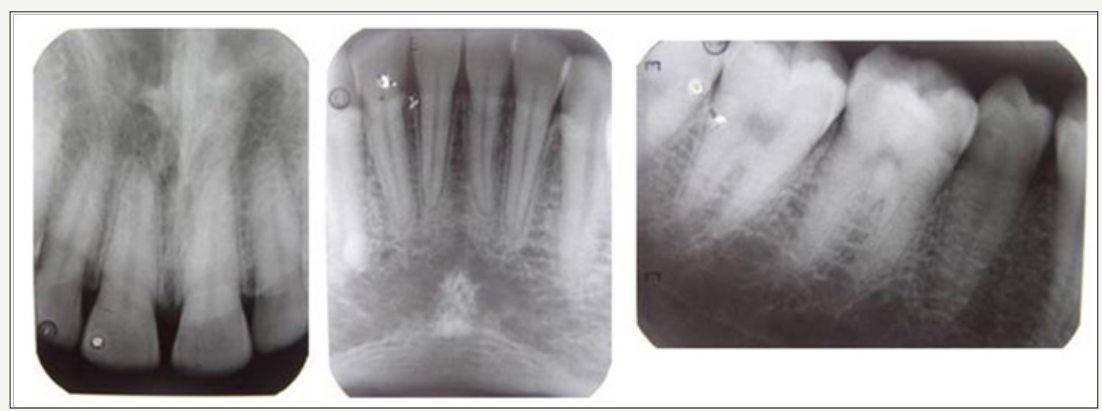

Figure 4A: Enamel radioopacity was not visible due to attritional loss. 4B: The thickness of the enamel appears unaltered.

IOPA: Maxillary and Mandibular Anteriors: Enamel radioopacity was not visible due to attritional loss (Figure 4A). Mandibular posteriors: Decreased contrast between enamel and dentine. The thickness of the enamel appears unaltered (Figure 4B).
Panoramic: There was adequate thickness of enamel on the occlusal surfaces of all the teeth. However, all the teeth showed a decreased contrast between the enamel and the dentine. The dentine and pulp chambers and root canals were radiographically normal as was the alveolar and basal bone (Figure 5).

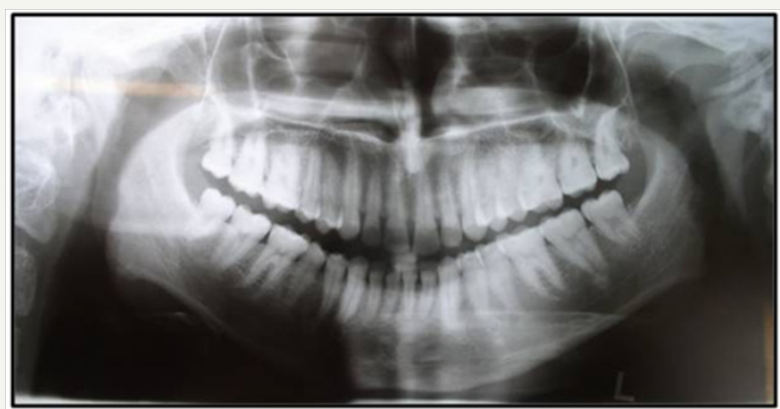

Figure 5: Dentine and pulp chambers and root canals were radiographically normal as was the alveolar and basal bone.

A final diagnosis of Amelogenesis Imperfecta- hypomaturation type was made based on the radiological diagnosis.

\section{Discussion}

Amelogenesis imperfecta (AI) represents a group of developmental conditions, which affect the structure and clinical appearance of enamel of all or nearly all the teeth in a more or less equal manner, and which may be associated with morphologic or biochemical changes elsewhere in the body [1]. Transmitted by either as autosomal dominant, autosomal recessive, or X-linked modes of inheritance, AI represents a rare problem that affects the oral health along with the quality of life of the affected patients [2]. 
Prevalence have been reported between 1 in 718 to 1 in 14,000, depending on the diagnostic criteria used. 60 to $73 \%$ of all cases being represented by Hypoplastic AI, 20 to $40 \%$ by hypo-maturation AI and $7 \%$ by hypo-calcification AI [3]. Originally AI was classified into hypoplastic and hypocalcified types. Many classifications have evolved since then [4].

Witkop [5] classified AI based primarily on phenotype, into four major categories: (hypoplastic, hypomaturation, hypocalcified, hypomaturation-hypoplastic with taurodontism). Witkop \& Rao [5] classification based on phenotype and mode of inheritance.

Three broad categories: hypoplastic, hypocalcificied, hypomaturation.

\section{Hypoplastic}

a. Autosomal dominant hypoplastic-hypomaturation with taurodontism (subdivded into $\mathrm{a}$ and $\mathrm{b}$ according to author)

b. Autosomal dominant smooth hypoplastic with eruption defect and resorption of teeth

c. Autosomal dominant rough hypoplastic

d. Autosomal dominant pitted hypoplastic

e. Autosomal dominant local hypoplastic

f. X-linked dominant rough hypoplastic

\section{Hypocalcified}

i. Autosomal dominant hypocalcified

\section{Hypomaturation}

A. X-linked recessive hypomaturation

B. Autosomal recessive pigmented hypomaturation

C. Autosomal dominant snow-capped teeth

D. White hypomature spots

From the various molecular genetic studies conducted, it was found that the etiology of AI may be due to the alteration of genes involved in the formation and maturation of the enamel (SHAFER) [6]. The Clinical presentation of the AI varies according to its type.

\section{Hypomaturation Al}

Inherited by autosomal dominant, recessive, or X-linked, the teeth are morphologically normal at the time of eruption, but may chip away post eruption, especially in the occlusal areas. Colour of teeth varies from creamy opaque to marked yellow/brown. Surface of teeth becomes soft and rough. Sensitivity increases due to dentinal exposure. The enamel thickness is almost always normal but often chips off easily. Radiographically, there is reduced contrast differentiation between enamel and dentin which makes it difficult to differentiate. Enamel has contrast similar to or greater than dentin. Unerupted crowns have normal morphology radiographically.

\section{Treatment}

As far as treatment is concerned, an endodontist and an orthodontist can work hand in hand with the paediatric dentist in planning the treatment right from an early age. The supportive care in terms of clinical and emotional needs is necessary [6]. While several authors prefer full porcelain restorations as the treatment modality, the advances in the field of esthetic dentistry, help practitioners to restore function and esthetics to an acceptable level [7].

\section{Conclusion}

Dental practitioners should take into consideration the emotional state of these patients and intervene to relieve their suffering. Multidisciplinary approach is important for the success of the treatment if accompanied by other dental anomalies. Last but not the least, patients should be counselled and motivated to maintain good oral hygiene.

\section{Ethical Approval}

The study was performed in accordance with the institutional ethical standards. Informed consent was obtained from all individual participants included in the study.

\section{References}

1. Crawford PJ, Aldred M, Bloch-Zupan A (2007) Amelogenesis imperfecta. Orphanet J Rare Dis 2: 17

2. Aldred MJ, Crawford PJ, Savarirayan R (2003) Amelogenesis imperfecta -a classification and catalogue for the $21^{\text {st }}$ century. Oral Dis $9(1): 19-23$.

3. Rajendran R (2007) Chapter 1. Developmental disturbances of oral and para oral structures. In: Rajendran R, Sivaparthasundaram B (Eds.) Shafer's Text book of Oral Pathology ( $5^{\text {th }}$ edn), Pub: Elsevier, Netherlands, p. 67.

4. Hemagaran G, Arvind M (2014) Amelogenesis imperfecta -literature review. Journal of Dental and Medical Sciences 13(1): 48-51.

5. Witkop CJ, Rao S (1971) Inherited defects in tooth structure. Birth Defects Orig Artic Ser 7(7): 153-184.

6. Hu JC, Chun YH, Al Hazzazzi T, Simmer JP (2007) Enamel formation and amelogenesis imperfecta. Cells Tissues Organs 186(1): 78-85.

7. Canger EM, Celenk P, Yenísey M, Odyakmaz SZ (2010) Amelogenesis imperfecta, hypoplastic type associated with some dental abnormalities: a case report. Braz Dent J 21(2): 170-174. 


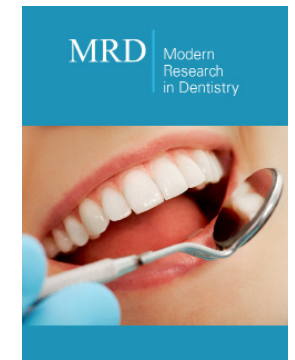

\section{Modern Research in Dentistry}

\section{Benefits of Publishing with us}

- High-level peer review and editorial services

- Freely accessible online immediately upon publication

- Authors retain the copyright to their work

- Licensing it under a Creative Commons license

- Visibility through different online platforms 